\title{
Comparison of surgical outcomes of trabeculectomy, Ahmed shunt, and Baerveldt shunt in uveitic glaucoma
}

\author{
Audrey Chow ${ }^{1}$, Bruce Burkemper ${ }^{1}$, Rohit Varma ${ }^{1}$, Damien C. Rodger ${ }^{2}$, Narsing Rao ${ }^{1}$ and Grace M. Richter ${ }^{1 *}$
}

\begin{abstract}
Background: Uveitis is defined as a collection of syndromes involving intraocular inflammation which can lead to pain, tissue damage, and vision loss. Ophthalmic surgery in uveitis patients can be challenging due to inflammation-induced fibrosis and scarring. Trabeculectomy and implantation of glaucoma drainage devices (aqueous shunts) have been used in surgical management of uveitic glaucoma, however there is a paucity of literature examining the comparative results of these entities in this unique setting. The purpose of this retrospective comparative study is to compare clinical outcomes of trabeculectomy with MMC, Ahmed shunt, and Baerveldt shunt surgery specifically in uveitic glaucoma.

Results: Median IOP, IOP reduction, glaucoma medication use, and visual acuity at 6- and 12-month follow-up were similar across groups. Postoperative hypotony rate was significantly different across trabeculectomy (53\%), Baerveldt (24\%), and Ahmed (18\%) groups ( $p=0.027)$; other complication rates were similar. Baerveldt eyes had a lower failure rate compared to trabeculectomy $(p=0.0054)$ and Ahmed $(p=0.0008)$ eyes.
\end{abstract}

Conclusions: While there was no difference in IOP reduction between trabeculectomy, Ahmed, and Baerveldt, Baerveldt eyes had the lowest failure rate.

Keywords: Glaucoma, Uveitis, Trabeculectomy, Ahmed, Baerveldt, Aqueous shunt

\section{Background}

Uveitis is defined as a collection of syndromes involving intraocular inflammation which can lead to pain, tissue damage, and vision loss $[1,2]$. With an estimated 109,000 cases of uveitis in the USA and 43,000 new cases a year, it is the third leading cause of preventable blindness in the developed world [3]. Twenty percent of patients with uveitis develop glaucoma due to inflammation or secondary to corticosteroid treatment of uveitis [2-4]. In uveitic glaucoma, elevated intraocular pressure results from increased resistance to aqueous outflow and can lead to irreversible optic nerve damage and eventual blindness [3].

Ophthalmic surgery in uveitis patients can be challenging due to inflammation-induced fibrosis and scarring.

\footnotetext{
* Correspondence: Grace.Richter@med.usc.edu

${ }^{1}$ Department of Ophthalmology, USC Roski Eye Institute, Keck Medicine of

University of Southern California, 1450 San Pablo Street, Suite 4700, Los

Angeles, CA 90033, USA

Full list of author information is available at the end of the article
}

However, surgical intervention may be indicated if intraocular pressure (IOP) cannot be adequately controlled by medications alone. These procedures include trabeculectomy and implantation of glaucoma drainage devices (aqueous shunts). Two types of aqueous shunts are the valved Ahmed shunt and the non-valved Baerveldt shunt [5]. Previous studies have separately demonstrated that trabeculectomy, Ahmed shunt, and Baerveldt shunt are all reasonably effective in controlling uveitic glaucoma [6-9]. Prior literature suggests that while trabeculectomy has good outcomes in uveitic glaucoma in the short term, the risk of failure is relatively high in the long term $[6,10-12]$. Bettis et al. compared the outcomes of trabeculectomy with mitomycin $\mathrm{C}(\mathrm{MMC})$ and Ahmed valve implantation and found that the Ahmed device was more effective than the trabeculectomy in uveitic eyes [13]. Iverson et al. showed that the non-valved Baerveldt device was also likely better than the trabeculectomy with MMC in controlling uveitic glaucoma [14]. Between the Ahmed and Baerveldt shunts, both the 
Ahmed Baerveldt Comparison Study (ABC) and the Ahmed Versus Baerveldt Study (AVB) found that Baerveldt patients had lower failure rates and lower median postoperative IOP but experienced more early postoperative complications, namely, hypotony [15-18]. However, these studies examined patients with glaucoma of a broad range of etiologies, not uveitic glaucoma specifically. Hypotony is especially relevant to uveitis where there is an increased risk of postoperative hypotony due to ciliary body inflammation and shutdown [4]. The Ahmed valve relies on the Venturi effect to open the valve for fluid outflow by facilitating a pressure differential when the pressure within the eye reaches an upper threshold $(8-12 \mathrm{~mm})$. The tension on the membranes within the valve is responsible for reducing hypotony due to overfiltration [19-21]. In the setting of low aqueous production, theoretically, the Ahmed valve has this additional mechanism in place to reduce hypotony, whereas the Baerveldt does not. While the risk of hypotony due to overfiltration would be lower with the Ahmed, there would still be hypotony if there were significant aqueous underproduction.

Direct comparison of outcomes of trabeculectomy with MMC, Ahmed, and Baerveldt surgery in uveitic patients is yet to be reported. The purpose of this retrospective comparative study is to compare clinical outcomes of these entities specifically in the setting of uveitic glaucoma. We hypothesized that trabeculectomies would have poorer outcomes than aqueous shunts due to persistent inflammation and postoperative scarring. Additionally, considering the increased risk hypotony in uveitic patients, we predicted that the valved Ahmed shunt would have lower rates of hypotony than the non-valved Baerveldt shunts in patients with uveitic glaucoma.

\section{Results and discussion}

A total of 147 eyes from 147 patients that met the study criteria were identified and reviewed. Seventeen eyes (17 patients) underwent trabeculectomy with MMC, 22 eyes (22 patients) underwent Ahmed implantation, and 108 eyes (108 patients) underwent Baerveldt implantation. One trabeculectomy, 11 Baerveldt, and 2 Ahmed eyes also underwent combined procedures with cataract extraction with intraocular lens implant at the time of glaucoma surgery. A total of 15 eyes underwent cataract surgery during the follow-up period.

Patient baseline demographics and ocular characteristics are summarized in Table 1 . There were no significant differences in these entities across groups. The median age of the study population was 62 years (19-96); $57 \%$ of the study population were female, and $14 \%$ were diabetic. The median IOP before surgery was $35 \mathrm{mmHg}(19-85)$ on four $(0-5)$ topical glaucoma medications and one $(0-3)$ topical anti-inflammatory medications. Forty-eight percent of patients were on systemic glaucoma medications, and $14 \%$ were on immunosuppressive medications. The median visual acuity was $0.7(0-3) \log$ MAR units. 110/147 $(75 \%)$ of patients had prior eye surgery, 22 of which had prior glaucoma filtering surgery. Fifty-nine percent eyes were pseudophakic with no significant difference in the proportion of pseudophakia across groups $(p=0.96)$. Fifty-eight percent of the eyes had idiopathic uveitis. The most common uveitis location in all groups was anterior uveitis $(n=127)$, and the most common known etiologies were herpes simplex virus $(n=18)$, uveitis-glaucoma-hyphema syndrome $(n=9)$, and Vogt-Koyanagi syndrome $(n=6)$. Other etiologies included sarcoidosis, birdshot, ankylosing spondylitis, juvenile rheumatoid arthritis, rheumatoid arthritis, syphilis, Posner-Schlossman syndrome, Fuch's heterochromic iridocyclitis, parasite, human leukocyte antigen B27, and tuberculosis.

As shown in Table 2, at 6-month follow-up, median IOP was reduced from $34(23-50)$ to $10(1-25) \mathrm{mmHg}$ in the trabeculectomy group, 40 (26-58) to $16(8-28)$ $\mathrm{mmHg}$ in the Ahmed group, and $33(19-85)$ to 12 (5-33) $\mathrm{mmHg}$ in the Baerveldt group $(p=0.015)$. Further, pairwise comparison showed that Ahmed IOP at 6 months was significantly higher than that of trabeculectomy $(p=0.02)$ and of Baerveldt $(p=0.0086)$, while there was no significant difference between trabeculectomy and Baerveldt $(p=0.32)$. Both the point and percent IOP reduction in trabeculectomy (22 (11-47) $\mathrm{mmHg}$, 69\% (41-97)), Ahmed (24 (7-40) $\mathrm{mmHg}, 65 \%$ (21-81)), and Baerveldt (21 (5-75) mmHg, 64\% (40-89)) groups were similar $(p=0.56)$. The median number of postoperative topical glaucoma medications was $0(1-3)$ in the trabeculectomy group, $2(0-4)$ in the Ahmed group, and $2(0-4)$ in the Baerveldt group $(p=0.098)$. The percentage of patients on systemic glaucoma medications postoperatively was $6 \%$ in the trabeculectomy group, $9 \%$ in the Ahmed group, and $6.5 \%$ in the Baerveldt group $(p=0.86)$. Topical glaucoma, anti-inflammatory, systemic glaucoma, immunosuppressive medication use, change in visual acuity, and rate of follow-up cataract surgery were similar in all groups.

Outcome measures at 12-month follow-up are shown in Table 3. At that time point, there was no significant difference in absolute IOP $(p=0.19)$, point IOP reduction $(p=0.62)$, or percent IOP reduction $(p=0.76)$ across groups. Median IOP, point IOP reduction, and percent IOP were $10 \quad(5-38) \mathrm{mmHg}, 22$ (10-39) $\mathrm{mmHg}$, and 69 (36-82)\%, respectively, in the trabeculectomy group; $14(6-27) \mathrm{mmHg}, 24(11-46) \mathrm{mmHg}$, $67(29-86) \%$, respectively, in the Ahmed group; and 12 (4-38) mmHg, 21 (8-76) $\mathrm{mmHg}$, and 65 (38-89)\%,respectively, in the Baerveldt group. The median number of 
postoperative topical glaucoma medications was $0(0-4)$ in the trabeculectomy group, 2 (0-4) in the Ahmed group, and $2(0-4)$ in the Baerveldt group $(p=0.22)$. The percentage of patients on systemic glaucoma medications postoperatively was $9 \%$ in the trabeculectomy group, $6 \%$ in the Ahmed group, and $4 \%$ in the Baerveldt group $(p=0.86)$. Again, there was also no difference in topical glaucoma, topical anti-inflammatory, systemic glaucoma, immunosuppressive medication use, change in visual acuity, or rate of follow-up cataract surgery between groups.

The type, rate, time, and total number of postoperative complications were similar in all groups $(p>0.05)$, except for hypotony (Tables 4 and 5 ). Specifically, there was a significant difference in early (6 weeks to 4 months postop) hypotony rate in trabeculectomy (47\%), Ahmed (18\%), and Baerveldt eyes (18.5\%) ( $p=0.027)$ but not for late (> 4 months postop) hypotony rate (trabeculectomy $6 \%$, Ahmed 0\%, Baerveldt 7\%) $(p=0.53)$.

Overall, the most common cause of failure was the failure of IOP control $(n=14)$; three trabeculectomy, five Ahmed, and five Baerveldt eyes failed due to IOP > $21 \mathrm{mmHg}$, and one Baerveldt eye failed due to persistent hypotony (defined as IOP $<5 \mathrm{mmHg}$ ). Two Baerveldt eyes lost light perception. One Ahmed was removed at a patient's request due to tube dysesthesia, and one Baerveldt was removed due to tube exposure. One patient received a possibly defective Ahmed with no bleb formation.

At 6-month follow-up, 0.9\% of Baerveldt eyes had failed, followed by $12 \%$ of trabeculectomy eyes and $14 \%$ of Ahmed eyes $(p=0.0063)$ (Table 2). This trend persisted through 12 months of follow-up, with Baerveldts at 3\%, trabeculectomy at $18 \%$, and Ahmed at 23\% ( $p=0.0015)$ failure rate (Table 3 ). Figure 1 illustrates the cumulative probability of failure in each group using Kaplan-Meier survival analysis. While the cumulative probability of failure was similar between the trabeculectomy and Ahmed groups $(p=0.93)$, the Baerveldt group had a significantly lower cumulative probability of failure than both the trabeculectomy $(p=0.0054$, Wilcoxon test) and the Ahmed ( $p=0.0008$, Wilcoxon test) groups (Table 6).

Univariate analyses were conducted to evaluate baseline demographic and ocular characteristics as possible risk factors for failure (Table 7). Consistent with our other findings, surgery type was a significant predictor of failure $(p=0.028)$. All other possible risk factors were not statistically significant $(p>0.05)$.

Table 8 describes the relative rates of failure between each group using logistic regression. Baerveldt eyes were $67 \%$ less likely than trabeculectomy eyes to fail (odds ratio 0.33 , 95\% CI $0.09-0.96$ ) and $73 \%$ less likely than Ahmed eyes to fail (odds ratio 0.27 , 95\% CI 0.09-0.85) overall. The odds ratio for Ahmed versus trabeculectomy failure was 1.22 (95\% CI 0.28-5.26).

This study comparing surgical outcomes of trabeculectomy, Ahmed shunt, and Baerveldt shunt in the eyes with uveitic glaucoma showed overall similar IOP control, medication use, and complication rates.

We found that all three treatments appear to be reasonably effective at controlling IOP to similar extents in the eyes with uveitic glaucoma, as previously reported [6-9]. At 12 months, IOP was comparable across groups, with no significant difference found. We observed a comparable decrease in glaucoma, anti-inflammatory, or immunosuppressant medication use in all three groups, with no significant difference in the degree of this reduction between groups. Notably, anti-inflammatory and immunosuppressant use did not increase in any group, demonstrating that these surgical treatment modalities at least did not worsen the uveitis.

The Ahmed group had significantly worse IOP control at 6 months follow-up compared to both trabeculectomy and Baerveldt groups. Previous studies have found that Ahmed shunts experience a higher incidence of hypertensive phase (IOP $>21 \mathrm{mmHg}$ ) that can last from 3 weeks to several months after surgery [22]. This hypertensive phase could potentially extend into the 6-month follow-up period, contributing to the higher 6-month IOP in Ahmed eyes found in our study. One theory for this observation is that immediate filtration causes an influx of inflammatory factors contained in the aqueous fluid; this stimulates a fibrotic response in the subconjunctival space, leading to bleb encapsulation [23]. It is probable that this fibrotic response may be exaggerated in uveitic glaucoma due to the inflammatory nature of uveitis. Notably, both the trabeculectomy and Baerveldt group also experienced greater rates of early hypotony compared to the Ahmed group, which could have additionally contributed to the disparity in IOP reduction. By 12 months, there was no longer a difference in IOP control between the three groups.

In the early postoperative phase specifically, trabeculectomy eyes had the highest rate of hypotony, followed by Baerveldt then Ahmed eyes. This is consistent with the results of the several previous large prospective randomized clinical trials. The Trabeculectomy Versus Tube study (TVT) comparing trabeculectomy versus Baerveldt shunt similarly found significantly higher rates of hypotony with trabeculectomy over Baerveldt shunt [24]. However, the TVT excluded uveitic eyes. With respect to Ahmed shunts, both the ABC study which included 18 uveitic eyes $(n=276)$ and AVB study which included 23 uveitic eyes $(n=238)$ observed greater risk of hypotony in Baerveldt over Ahmed eyes [18, 25, 26]. 
Table 1 Baseline demographics and ocular characteristics

\begin{tabular}{|c|c|c|c|c|c|}
\hline & $\begin{array}{l}\text { Total } \\
n=147 \text { eyes }\end{array}$ & $\begin{array}{l}\text { Trabeculectomy } \\
n=17 \text { eyes }\end{array}$ & $\begin{array}{l}\text { Ahmed } \\
n=22 \text { eyes }\end{array}$ & $\begin{array}{l}\text { Baerveldt } \\
n=108 \text { eyes }\end{array}$ & $p$ value \\
\hline Age (years), M (range) & $62(19-96)$ & $54(19-72)$ & $61(22-86)$ & $62(20-96)$ & $0.15^{*}$ \\
\hline Sex, female, \% (n) & $57(84)$ & $59(10)$ & $50(11)$ & $58(63)$ & $0.70^{\S}$ \\
\hline Diabetes, \% (n) & $14(20)$ & $6(1)$ & $9(2)$ & $16(17)$ & $0.57^{\dagger}$ \\
\hline Preop IOP (mmHg), M (range) & $35(19-85)$ & $34(23-50)$ & $40(26-58)$ & $33(19-85)$ & $0.066^{*}$ \\
\hline Preop visual acuity (logMAR), M (range) & $0.7(0-3)$ & $0.5(0-3)$ & $0.6(0-3)$ & $0.8(0-3)$ & $0.34^{*}$ \\
\hline Preop number of topical glaucoma medications, M (range) & $4(0-5)$ & $4(0-1)$ & $3(0-4)$ & $4(0-5)$ & $0.15^{*}$ \\
\hline Preop on systemic glaucoma medications, \% ( $n$ ) & $48(70)$ & $53(9)$ & $55(12)$ & $45(49)$ & $0.66^{\dagger}$ \\
\hline Preop number of topical anti-inflammatory medications, M (range) & $1(0-3)$ & $1(0-2)$ & $1(0-2)$ & $1(0-3)$ & $0.82^{*}$ \\
\hline Preop on systemic immunosuppressants, \% ( $n$ ) & $14(21)$ & $18(3)$ & $18(4)$ & $13(14)$ & $0.63^{\dagger}$ \\
\hline Prior eye surgery, $\%(n)$ & $75(110)$ & $82(14)$ & $75(81)$ & $68(15)$ & $0.60^{\S}$ \\
\hline Prior glaucoma surgery, \% ( $n)$ & $15(22)$ & $24(4)$ & $14(3)$ & $14(15)$ & $0.22^{\S}$ \\
\hline Pseudophakia, \% (n) & $56(82)$ & $53(9)$ & $55(12)$ & $56(61)$ & $0.96^{\dagger}$ \\
\hline \multicolumn{6}{|l|}{ Uveitis location, $n(\%)$} \\
\hline Anterior & $127(86)$ & $13(76)$ & $20(90)$ & $94(87)$ & \\
\hline Intermediate & $4(3)$ & $1(6)$ & $0(0)$ & $3(3)$ & \\
\hline Posterior & $4(3)$ & $2(12)$ & $1(5)$ & $1(0.9)$ & \\
\hline Pan & $12(8)$ & $1(6)$ & $1(5)$ & $10(9)$ & \\
\hline \multicolumn{6}{|l|}{ Etiology, $n(\%)$} \\
\hline Idiopathic & $91(62)$ & $12(71)$ & $11(50)$ & $69(64)$ & \\
\hline Herpes simplex virus & $18(12)$ & $2(12)$ & $1(5)$ & $15(14)$ & \\
\hline Sarcoidosis & $1(0.7)$ & $0(0)$ & $0(0)$ & $1(0.9)$ & \\
\hline Birdshot & $1(0.7)$ & $0(0)$ & $1(5)$ & $0(0)$ & \\
\hline Ankylosing spondylitis & $2(1)$ & $0(0)$ & $2(9)$ & $0(0)$ & \\
\hline Vogt-Koyanagi syndrome & $6(4)$ & $1(6)$ & $2(9)$ & $3(3)$ & \\
\hline Juvenile rheumatoid arthritis & $3(2)$ & $1(6)$ & $1(5)$ & $1(0.9)$ & \\
\hline Uveitis-glaucoma-hyphema syndrome & $9(6)$ & $0(0)$ & $1(5)$ & $8(7)$ & \\
\hline Rheumatoid arthritis & $5(3)$ & $1(6)$ & $0(0)$ & $4(4)$ & \\
\hline Syphilis & $1(0.7)$ & $0(0)$ & $1(5)$ & $0(0)$ & \\
\hline Posner-Schlossman syndrome & $1(0.7)$ & $0(0)$ & $0(0)$ & $1(0.9)$ & \\
\hline Fuch's heterochromic iridocyclitis & $1(0.7)$ & $0(0)$ & $0(0)$ & $1(0.9)$ & \\
\hline Parasite & $2(1)$ & $0(0)$ & $2(9)$ & $0(0)$ & \\
\hline HLA B27 & $4(3)$ & $0(0)$ & $0(0)$ & $4(4)$ & \\
\hline Tuberculosis & $1(0.7)$ & $0(0)$ & $0(0)$ & $1(0.9)$ & \\
\hline
\end{tabular}

IOP intraocular pressure, IogMAR logarithm of minimum angle of resolution, HLA human leukocyte antigen

${ }^{*}$ Kruskal-Wallis test; ${ }^{\dagger}$ Fisher's exact test; ${ }^{\S}$ chi-squared test

Interestingly, while $4.5 \%$ of Ahmed eyes and $11 \%$ of Baerveldt eyes experienced uveitic flares during the early or late postoperative period, there were no instances of this in trabeculectomy eyes. This may well be due to sampling bias, as uveitic eyes with greater inflammation at baseline may be seen as poor candidates for trabeculectomy, and thus are more likely to receive a shunt. Alternatively, this difference may be due to aqueous shunt implants inducing more inflammation than trabeculectomy with MMC. The placement of a foreign material like silicone may incite an inflammatory response; silicone has a high affinity for plasma proteins and a tendency to activate inflammatory mediators as well as stimulate fibrosis $[27,28]$. This would be particularly unfavorable in uveitic patients who are already predisposed to severe inflammation.

Notably, both shunts tended to experience more corneal decompensation than trabeculectomy. Corneal complications associated with shunts have been observed in previous studies $[27,29]$. In our study, 
Table 2 Six-month postoperative outcome

\begin{tabular}{|c|c|c|c|c|c|}
\hline & $\begin{array}{l}\text { Total } \\
n=147 \text { eyes }\end{array}$ & $\begin{array}{l}\text { Trabeculectomy } \\
n=17 \text { eyes }\end{array}$ & $\begin{array}{l}\text { Ahmed } \\
n=22 \text { eyes }\end{array}$ & $\begin{array}{l}\text { Baerveldt } \\
n=108 \text { eyes }\end{array}$ & $p$ value \\
\hline $\mathrm{IOP}(\mathrm{mmHg}), \mathrm{M}$ (range) & $12(1-33)$ & $10(1-25)$ & $16(8-28)$ & $12(5-33)$ & $0.015^{*}$ \\
\hline Visual acuity (logMAR), M (range) & $0.7(0-3)$ & $0.4(0-3)$ & $1(0-3)$ & $0.7(0-3)$ & $0.14^{*}$ \\
\hline Number of topical glaucoma medications, M (range) & $2(0-4)$ & $0(0-3)$ & $2(0-4)$ & $2(0-4)$ & $0.098^{*}$ \\
\hline On systemic glaucoma medications, \% ( $n$ ) & $7(10)$ & $6(1)$ & $9(2)$ & $6.5(7)$ & $0.86^{+}$ \\
\hline Number of topical anti-inflammatory medications, M (range) & $1(0-3)$ & $1(0-2)$ & $1(0-2)$ & $1(0-3)$ & $0.77^{*}$ \\
\hline On systemic immunosuppressants, \% (n) & $10(14)$ & $6(1)$ & $2(3)$ & $9(10)$ & $0.65^{\S}$ \\
\hline IOP reduction (mmHg), M (range) & $22(5-75)$ & $22(11-47)$ & $24(7-40)$ & $21(5-75)$ & $0.56^{*}$ \\
\hline \% IOP reduction, M (range) & $65(26-100)$ & $69(41-97)$ & $65(21-81)$ & $64(40-89)$ & $0.43^{*}$ \\
\hline Change in visual acuity (logMar), M (range) & $0(-3-2)$ & $-0.1(-1-2)$ & $0(-2-2)$ & $0(-3-2)$ & $0.52^{*}$ \\
\hline Lost $>2$ lines in visual acuity, \% ( $n$ ) & $25(36)$ & $6(1)$ & $31(7)$ & $26(28)$ & $0.14^{\S}$ \\
\hline Cataract surgery during follow up period, $\%(n)$ & $5(7)$ & $0(0)$ & $5(1)$ & $6(6)$ & $1^{+}$ \\
\hline Failure, \% (n) & $4(6)$ & $12(2)$ & $14(3)$ & $0.9(1)$ & $0.0063^{\dagger}$ \\
\hline
\end{tabular}

Failure was defined as postoperative intraocular pressure greater than $21 \mathrm{mmHg}$ or less than $5 \mathrm{mmHg},<20 \%$ IOP reduction, reoperation, or loss of light perception

$I O P$ intraocular pressure, logMAR logarithm of minimum angle of resolution

*Kruskal-Wallis test; ${ }^{\dagger}$ Fisher's exact test; ${ }^{\S}$ chi-squared test

Baerveldt eyes trended towards greater rates of corneal complications compared to Ahmed eyes, a finding that was significant in the $\mathrm{ABC}$ and $\mathrm{ABV}$ studies [15-18]. One case report observed backflow of aqueous fluid toward the cornea in a Baerveldt shunt, a possible mechanism of corneal damage [28].

Overall, Baervelt eyes appear to experience more complications than the other treatment groups. Specifically, both the $\mathrm{ABC}$ and $\mathrm{ABV}$ studies found more complications associated with Baerveldt than Ahmed eyes [15-18].
Iverson et al. found similar complication rates between Baerveldts and trabeculectomies specifically in uveitic eyes, which echoed the findings in the TVT study. However, the TVT study was a relatively smaller study $(n=76)$, and it did not include uveitic eyes [14, 24]. In our study, we observed a pattern of Baerveldt eyes experiencing greater early and late number of complications, with a trend towards significance. They tended to have more persistent hypotony in the late postoperative period. This could be related to the lack of a valve along with the larger

Table 3 Twelve-month postoperative outcome

\begin{tabular}{|c|c|c|c|c|c|}
\hline & $\begin{array}{l}\text { Total } \\
n=115 \text { eyes }\end{array}$ & $\begin{array}{l}\text { Trabeculectomy } \\
n=11 \text { eyes }\end{array}$ & $\begin{array}{l}\text { Ahmed } \\
n=17 \text { eyes }\end{array}$ & $\begin{array}{l}\text { Baerveldt } \\
n=87 \text { eyes }\end{array}$ & $p$ value \\
\hline$\overline{\mathrm{IOP}}(\mathrm{mmHg}), \mathrm{M}$ (range) & $12(4-38)$ & $10(5-38)$ & $14(6-27)$ & $12(4-38)$ & $0.19^{*}$ \\
\hline Visual acuity (logMAR) M (range) & $0.6(0-3)$ & $0.2(0-1)$ & $0.5(0-3)$ & $0.7(0-3)$ & $0.097^{*}$ \\
\hline Number of topical glaucoma medications, M (range) & $2(0-4)$ & $0(0-4)$ & $2(0-4)$ & $2(0-4)$ & $0.22^{*}$ \\
\hline On systemic glaucoma medications, \% ( $n$ ) & $5(6)$ & $9(1)$ & $6(1)$ & $4(4)$ & $0.59^{\dagger}$ \\
\hline Number of topical anti-inflammatory medications, M (range) & $1(0-2)$ & $1(0-2)$ & $1(0-2)$ & $1(0-2)$ & $0.69^{*}$ \\
\hline On systemic immunosuppressants, \% (n) & $5(6)$ & $9(1)$ & $6(1)$ & $4(4)$ & $0.59^{+}$ \\
\hline IOP reduction (mmHg), M (range) & $22(10-76)$ & $22(10-39)$ & $24(11-46)$ & $21(8-76)$ & $0.62^{*}$ \\
\hline$\%$ IOP reduction, $\mathrm{M}$ (range) & $66(-38-89)$ & $69(36-82)$ & $67(29-86)$ & $65(38-89)$ & $0.76^{*}$ \\
\hline Change in visual acuity (logMar), M (range) & $0(-3-2)$ & $-0.3(-1-0.2)$ & $0(-1-2)$ & $0(-3-2)$ & $0.48^{*}$ \\
\hline Lost $>2$ lines in visual acuity, \% (n) & $33(38)$ & $36(4)$ & $41(7)$ & $31(27)$ & $0.70^{\S}$ \\
\hline Cataract surgery during follow up period, $\%(n)$ & $13(15)$ & $0(0)$ & $6(1)$ & $16(14)$ & $0.35^{\dagger}$ \\
\hline Failure, \% (n) & $7.5(11)$ & $18(3)$ & $23(5)$ & $3(3)$ & $0.0015^{\dagger}$ \\
\hline
\end{tabular}

Further pairwise comparison showed a significant difference in 6 months IOP in Ahmed versus trabeculectomy $(p=0.02)$ and Ahmed versus Baerveldt $(p=0.0086)$. There was no significant difference in 6 months IOP between trabeculectomy versus Baerveldt $(p=0.32)$

Failure was defined as postoperative intraocular pressure greater than $21 \mathrm{mmHg}$ or less than $5 \mathrm{mmHg},<20 \%$ IOP reduction, reoperation, or loss of light perception

$I O P$ intraocular pressure, logMAR logarithm of minimum angle of resolution

${ }^{*}$ Kruskal-Wallis test; ${ }^{\dagger}$ Fisher's exact test; ${ }^{\circledR}$ chi-squared test 
Table 4 Early postoperative complications

\begin{tabular}{|c|c|c|c|c|c|}
\hline \multirow[t]{2}{*}{ Complication, \% (n) } & \multirow{2}{*}{$\begin{array}{l}\text { Total } \\
n=147 \text { eyes }\end{array}$} & \multirow{2}{*}{$\begin{array}{l}\text { Trabeculectomy } \\
n=17 \text { eyes }\end{array}$} & \multirow{2}{*}{$\begin{array}{l}\text { Ahmed } \\
n=22 \text { eyes }\end{array}$} & \multirow{2}{*}{$\begin{array}{l}\text { Baerveldt } \\
n=108 \text { eyes }\end{array}$} & \multirow[t]{2}{*}{$p$ value } \\
\hline & & & & & \\
\hline Hypotony & $22(32)$ & $47(8)$ & $18(4)$ & $19(20)$ & 0.027 \\
\hline Choroidal effusion & $11(16)$ & $0(0)$ & $9(2)$ & $13(14)$ & 0.34 \\
\hline Cystoid macular edema & $5(8)$ & $6(1)$ & $0(0)$ & $7(7)$ & 0.70 \\
\hline Hyphema & $8(11)$ & $12(2)$ & $9(2)$ & $7(7)$ & 0.59 \\
\hline Shallow anterior chamber & $3(5)$ & $6(1)$ & $0(0)$ & $4(4)$ & 0.57 \\
\hline Corneal edema/decompensation & $17(25)$ & $6(1)$ & $9(2)$ & $20(22)$ & 0.26 \\
\hline Uveitic flare & $9(13)$ & $0(0)$ & $4.5(1)$ & $11(12)$ & 0.44 \\
\hline Diplopia/strabismus & $0.7(1)$ & $0(0)$ & $0(0)$ & $0.9(1)$ & 1 \\
\hline Blocked tube & $0.7(1)$ & & $0(0)$ & $0.9(1)$ & 1 \\
\hline Erosion & $2(3)$ & & $5(1)$ & $2(2)$ & 0.43 \\
\hline Revision & $8(12)$ & $6(1)$ & $5(1)$ & $9(10)$ & 0.87 \\
\hline Patients with complications & $69(101)$ & $65(11)$ & $68(15)$ & $69(75)$ & 0.92 \\
\hline Total number of complications & $2(220)$ & $1(21)$ & $1(27)$ & $2(172)$ & 0.26 \\
\hline
\end{tabular}

Early postoperative complications were defined as complications occurring within 6 weeks to 4 months after surgery. The Fisher's exact test was used for statistical analysis

drainage plate size of Baerveldts, leading to overfiltration. However, there have been mixed results on whether a robust correlation between end plate size and IOP reduction exists [22, 30-33]. While we were concerned that this tendency for hypotony with Baerveldt shunts coupled with postoperative ciliary body shutdown in uveitic glaucoma would produce worse outcomes, the vast majority of failures overall were still due to high IOP; only one failure was attributed to persistent hypotony, which was in a Baerveldt eye.

While Baerveldt eyes tended to experience more complications, they ultimately had the lowest failure rate at 6- and 12-month follow-up as well as the lowest overall cumulative probability of failure (Tables 2 and 3, Fig. 1). While the rate of failure found in previous studies has been widely variable, the Baerveldt failure rates have consistently been lower than that of trabeculectomy and Ahmed within each prior study [14-18, 24]. Specifically, at 12-month follow-up, we found failure rates of 3,18 , and $23 \%(p=0.0015)$ in Baerveldt, trabeculectomy, and Ahmed eyes, respectively.

While Bettis et al. observed better cumulative success rate with Ahmed shunts than trabeculectomies in uveitic eyes, we did not find a significant difference between these entities [13]. Possible factors for the difference in results between studies include relatively small sample

Table 5 Late postoperative complications

\begin{tabular}{|c|c|c|c|c|c|}
\hline \multirow[t]{2}{*}{ Complication, \% (n) } & \multirow{2}{*}{$\begin{array}{l}\text { Total } \\
n=147 \text { eyes }\end{array}$} & \multirow{2}{*}{$\begin{array}{l}\text { Trabeculectomy } \\
n=17 \text { eyes }\end{array}$} & \multirow{2}{*}{$\begin{array}{l}\text { Ahmed } \\
n=22 \text { eyes }\end{array}$} & \multirow{2}{*}{$\begin{array}{l}\text { Baerveldt } \\
n=108 \text { eyes }\end{array}$} & \multirow[t]{2}{*}{$p$ value } \\
\hline & & & & & \\
\hline Hypotony & $6(9)$ & $6(1)$ & $0(0)$ & 7 (8) & 0.53 \\
\hline Choroidal effusion & $1(2)$ & $0(0)$ & $5(1)$ & $0.9(1)$ & 0.46 \\
\hline Cystoid macular edema & $6(9)$ & $6(1)$ & $5(1)$ & 7 (8) & 0.14 \\
\hline Hyphema & $1(2)$ & $0(0)$ & $0(0)$ & $2(2)$ & 1 \\
\hline Shallow anterior chamber & $0(0)$ & $0(0)$ & $0(0)$ & $0(0)$ & 1 \\
\hline Corneal edema/decompensation & $12(18)$ & $6(1)$ & $5(1)$ & $15(16)$ & 0.41 \\
\hline Uveitic flare & $0.7(1)$ & $0(0)$ & $0(0)$ & $0.9(1)$ & 1 \\
\hline Diplopia/strabismus & $1(2)$ & $0(0)$ & $5(1)$ & $0.9(1)$ & 0.46 \\
\hline Blocked tube & $2(3)$ & & $0(0)$ & $3(3)$ & 1 \\
\hline Erosion & $3(5)$ & & $9(2)$ & $3(3)$ & 0.20 \\
\hline Revision & $9(13)$ & $0(0)$ & $24(5)$ & $8(9)$ & 0.055 \\
\hline Patients with complications & $38(56)$ & $24(4)$ & $46(10)$ & $39(42)$ & 0.36 \\
\hline Total number of complications & $0.8(110)$ & $0.4(6)$ & $0.8(17)$ & $0.8(87)$ & 0.12 \\
\hline
\end{tabular}

Late postoperative complications were defined as complications occurring $>4$ months after surgery. The Fisher's exact test was used for statistical analysis 


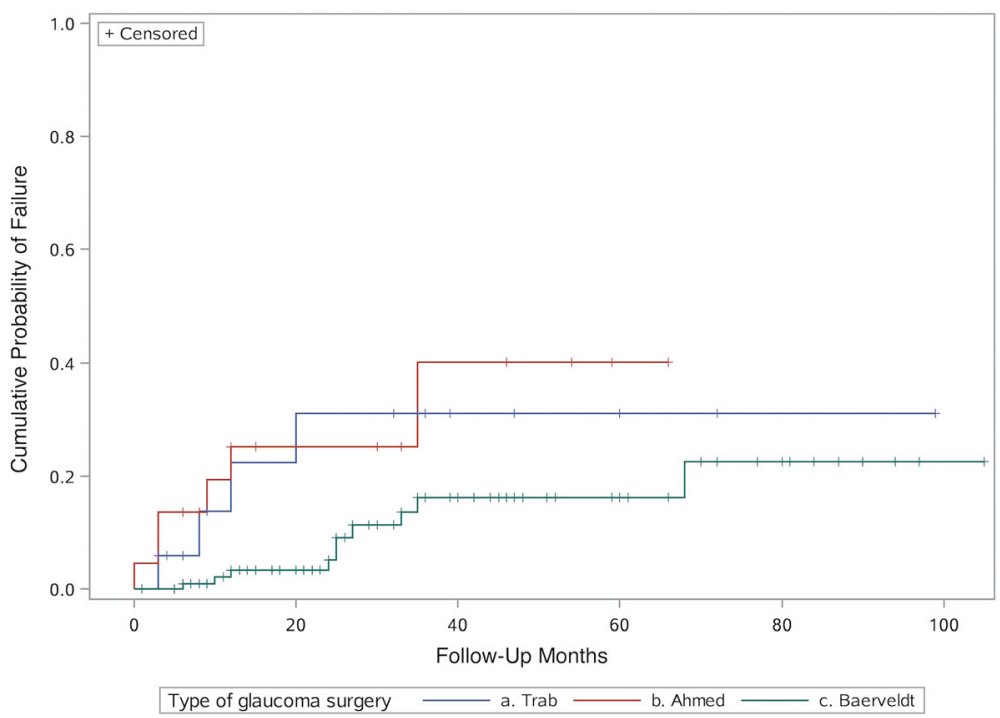

Fig. 1 Cumulative probability of failure from any cause. Kaplan-Meier curves showing cumulative probability of failure from any cause. Ahmed and trabeculectomy were similar ( $p=0.93$, Wilcoxon test). Baerveldt differed significantly from trabeculectomy $(p=0.0054$, Wilcoxon test) and from Ahmed ( $p=0.0008$, Wilcoxon test)

size $(n=22)$ in our study and trend towards higher baseline preoperative IOP in the Ahmed group.

One eye in this group received a possibly defective Ahmed device, as a bleb never formed and IOP remained high despite a clear tube. This patient was also allergic to most glaucoma medications and was less able to control IOP. These factors may have disproportionately negatively affected the overall results of the Ahmed group given the relatively small group size $(n=22)$ in this study.

With regard to IOP, consistent with $\mathrm{AVB}$ and $\mathrm{ABC}$ studies, Ahmed eyes had higher postoperative pressures at both 6-month (16 (8-28) $\mathrm{mmHg}, p=0.015)$ and 12-month (14 (6-27) mmHg, $p=0.19)$ follow-up. However, they also trended towards the greatest IOP point and percent reduction. This suggests that the Ahmed valves were at least as effective as the other treatments at reducing IOP.

It is possible that physicians may be more likely to place Ahmed shunts in patients with higher IOPs that need immediate relief because trabeculectomy may drop the IOP too quickly, while the Baerveldt shunt with tubal ligation would take up to 6 weeks for the sutures to dissolve and open. It could be speculated that patients

Table 6 Cumulative failure analysis

\begin{tabular}{ll}
\hline & $p$ value \\
\hline Ahmed vs. trabeculectomy & 0.93 \\
Baerveldt vs trabeculectomy & 0.0054 \\
Baerveldt vs. Ahmed & 0.0008 \\
\hline
\end{tabular}

The Wilcoxon test was used for statistical analysis with severe IOP elevation may benefit most from an Ahmed shunt implant.

This study has potential limitations associated with its retrospective design. These weaknesses include possible selection bias, inconsistent follow-up, and lack of randomization to treatment groups. Fortunately, baseline demographics were similar between our treatment groups. The Kaplan-Meier analysis was

Table 7 Univariate predictors of failure

\begin{tabular}{ll}
\hline Variable & $p$ value \\
\hline Sex & $0.057^{\S}$ \\
Race & $0.14^{*}$ \\
Smoking & $0.25^{\dagger}$ \\
Alcohol & $0.70^{\dagger}$ \\
Diabetes & $0.39^{*}$ \\
Family history of glaucoma & $0.48^{*}$ \\
Pseudophakia & $0.91^{\S}$ \\
History of eye surgery & $0.14^{\S}$ \\
History of Glc filtration surgery & $0.26^{\S}$ \\
History of failed trabeculectomy & $0.56^{\S}$ \\
Prednisone & $0.71^{\dagger}$ \\
Uveitis location & $0.68^{\S}$ \\
Surgery type & $0.81^{\dagger}$ \\
Preoperative IOP & $0.028^{\dagger}$ \\
Cataract surgery in follow-up period & $0.12^{\S}$ \\
\hline
\end{tabular}

Glc glaucoma, IOP intraocular pressure

${ }^{*}$ Kruskal-Wallis test; ${ }^{\dagger}$ Fisher's exact test; ${ }^{\S}$ chi-squared test 
Table 8 Odds ratio of failure

\begin{tabular}{lll}
\hline Comparison & Odds ratio & $95 \%$ confidence interval \\
\hline Ahmed vs. trabeculectomy & 1.22 & $0.28-5.26$ \\
Baerveldt vs trabeculectomy & 0.33 & $0.09-0.96$ \\
Baerveldt vs. Ahmed & 0.27 & $0.09-0.85$ \\
\hline
\end{tabular}

used to compare failure rates despite unequal follow-up. The vast majority of our patients had anterior uveitis. While we are unable to comment on any differential effects on anatomical uveitic classifications or uveitic etiologies, this would be a topic of interest for future research. We also had a relatively large disparity in sample sizes between treatment groups. Relatively small trabeculectomy and Ahmed group sizes (particularly trabeculectomy) compared to Baerveldt group size limit the power of our statistical analyses, including that of the pairwise comparisons and logistic regression. Additional eyes in these groups to increase and equalize sample sizes may have better powered our results.

\section{Conclusions}

In summary, we found no difference in median IOP reduction or medication use at 6- and 12-month follow-up between trabeculectomy with MMC, Ahmed shunt, and Baerveldt shunt in patients with uveitic glaucoma. Complication rates were similar with the exception of hypotony; the trabeculectomy group had a higher rate of early hypotony, while the Baerveldt group trended towards a higher rate of late hypotony. Baerveldt eyes had significantly lower failure rates at 6-and 12-month follow-up, as well as lowest overall cumulative failure rate. Prospective, randomized controlled trials are needed to further explore the comparative effects of these surgical treatments in the eyes with uveitic glaucoma.

\section{Methods}

We retrospectively reviewed the records of 147 eyes (17 trabeculectomy with MMC, 22 Ahmed, 108 Baerveldt) from 147 patients who underwent ophthalmic surgery for uveitic glaucoma at the University of Southern California Department of Ophthalmology between 2005 and 2014. Exclusion criteria included patients with $<6$ months of follow up. This study was reviewed and approved by the Institutional Review Board at the University of Southern California.

All procedures were performed in a standard fashion, as briefly described below. For all groups, the eyes received subconjunctival injections of cefazolin and dexamethasone and topical steroid-antibiotic ointment before being patched at the end of the procedure.
For trabeculectomy, a fornix-based conjunctival flap was created in the superior quadrant. Next, a $4 \times 3-\mathrm{mm}$ trapezoidal half scleral thickness flap was made. An MMC $0.5 \mathrm{mg} / \mathrm{mL}$ soaked sponge was then applied under the conjunctival flap for 2 min, which was irrigated copiously with balanced salt solution afterwards. A Kelly punch was used to create a sclerostomy at the limbus. The corners of the scleral flap were then sutured down, and the overlying Tenon and conjunctival tissues were re-approximated and closed.

For the Ahmed placement, a conjunctival periotomy was created. An Ahmed FP-7 implant was placed $8 \mathrm{~mm}$ posterior to the limbus in either in the superonasal or superotemporal quadrants and anchored to the sclera with two 8-0 nylon sutures. The tube was trimmed to an appropriate length with a beveled tip. A sclerostomy was made, and the tube is inserted into the anterior chamber through the sclerostomy. The tube was then affixed to the sclera and covered with a Tutoplast scleral patch graft. Overlying Tenon and conjunctival tissues were re-approximated and closed.

For the Baerveldt placement, a conjunctival periotomy was created. A Baerveldt-250 or Baervedlt-350 implant was placed either in the superonasal or superotemporal quadrants below the rectus muscles and anchored to the sclera with two 8-0 nylon sutures. The tube was then ligated with an absorbable 6-0 vicryl suture for hypotony prevention. When tube fenestration was performed, this was done with the needle of the 6-0 vicryl suture. The tube was trimmed to an appropriate length with a beveled tip. A sclerostomy was made, and the tube is inserted into the anterior chamber through the sclerostomy. The tube was then affixed to the sclera and covered with a Tutoplast scleral patch graft. Overlying Tenon and conjunctival tissues were re-approximated and closed.

Data were collected at baseline visits prior to surgery and at 6 and 12 months after surgery. Baseline demographic and ocular characteristics such as sex, age, medical comorbidities, uveitis etiology and location, and other ophthalmic history were collected. We also recorded preoperative and postoperative IOP, best-corrected visual acuity, topical and systemic glaucoma medications, systemic immunosuppressant use, postoperative complications, and reoperations. Postoperative complications included hypotony, choroidal effusion, cystoid macular edema, corneal edema/decompensation, and severe inflammation. Complications were divided into early complications (6 weeks to 4 months after surgery) and late complications ( $>4$ months after surgery).

The primary outcome measures were IOP reduction and failure rate. Failure was defined as one of the following: IOP out of target range $(5-21 \mathrm{mmHg}),<20 \%$ reduction from baseline at two consecutive follow-up visits after 3 months, glaucoma reoperation, or loss of light perception [17]. 
Statistical analysis was performed using SAS 9.4 (SAS Institute Inc., Cary, NC, USA). Snellen visual acuity measurements were converted to logMAR equivalents. Descriptive statistics were performed to compare baseline demographic and ocular characteristics among treatment groups. Continuous variables were analyzed using the Kruskal-Wallis test, and categorical variables were analyzed using the Pearson's chi-squared test and Fisher's exact test.

The Pearson chi-squared test, Fisher's exact test, and Kruskal-Wallis test were performed to identify potential risk factors for failure. Logistic regression was used to determine the relative risk of failure among treatment groups. Time to failure was estimated using Kaplan-Meier curves and compared using the Wilcoxon test.

Statistical significance was defined as $p<0.05$.

\section{Abbreviations}

ABC: Ahmed Baerveldt Comparison Study; AVB: Ahmed Versus Baerveldt Study; Glc: Glaucoma; HLA: Human leukocyte antigen; IOP: Intraocular pressure; logMAR: Logarithm of minimum angle of resolution; MMC: Mitomycin C; TVT: Trabeculectomy Versus Tube Study; USC: University of Southern California

\section{Acknowledgements}

This study has been supported by the Keck Summer Research Fellowship at the Keck School of Medicine (AC), the American Glaucoma Society Mentoring for the Advancement of Physician Scientists award (GMR), and an unrestricted grant from the Research to Prevent Blindness Foundation to the USC Department of Ophthalmology.

\section{Availability of data and materials}

Please contact the authors for data requests.

\section{Authors' contributions}

AC participated in the design and coordination of the study, performed the data collection, contributed to the study's analyses, and drafted the manuscript. BB performed the statistical analysis. RV, DCR, and NR helped conceive the study and contributed to the study analysis. GMR conceived the study, participated in its design and analysis, and helped draft the manuscript. All authors read and approved the final manuscript.

\section{Ethics approval and consent to participate}

This study was reviewed and approved by the Institutional Review Board at the University of Southern California.

\section{Competing interests}

The authors declare that they have no competing interests.

\section{Publisher's Note}

Springer Nature remains neutral with regard to jurisdictional claims in published maps and institutional affiliations.

\footnotetext{
Author details

'Department of Ophthalmology, USC Roski Eye Institute, Keck Medicine of University of Southern California, 1450 San Pablo Street, Suite 4700, Los Angeles, CA 90033, USA. ²Department of Ophthalmology, Kaiser Permanente Los Angeles Medical Center, 1515 N. Vermont Ave, 7th floor, Los Angeles, CA 90027, USA.

Received: 22 February 2018 Accepted: 8 May 2018

Published online: 18 June 2018

\section{References}

1. Wakefield D, Chang JH (2005) Epidemiology of uveitis. Int Ophthalmol Clin 45(2):1-13
}

2. Moorthy RS, Mermoud A, Baerveldt G et al (1997) Glaucoma associated with uveitis. Surv Ophthalmol 41:361-394

3. Siddique SS, Suelves AM, Baheti U, Foster CS (2013) Glaucoma and uveitis. Surv Ophthalmol 58(1):1-10

4. Friedman DS, Holbrook JT, Ansari $\mathrm{H}$ et al (2013) Risk of elevated intraocular pressure and glaucoma in patients with uveitis: results of the multicenter uveitis steroid treatment trial. Ophthalmology 120:1571-1579

5. Muñoz-negrete FJ, Moreno-montañés J, Hernández-martínez P, Rebolleda G (2015) Current approach in the diagnosis and management of uveitic glaucoma. Biomed Res Int 2015:742792

6. Ceballos EM, Beck AD, Lynn MJ (2002) Trabeculectomy with antiproliferative agents in uveitic glaucoma. J Glaucoma 11(3):189-196

7. Ozdal PC, Vianna RN, Deschênes J (2006) Ahmed valve implantation in glaucoma secondary to chronic uveitis. Eye (Lond) 20(2):178-183

8. Papadaki TG, Zacharopoulos IP, Pasquale LR, Christen WB, Netland PA, Foster CS (2007) Long-term results of Ahmed glaucoma valve implantation for uveitic glaucoma. Am J Ophthalmol 144(1):62-69

9. Ceballos EM, Parrish RK, Schiffman JC (2002) Outcome of Baerveldt glaucoma drainage implants for the treatment of uveitic glaucoma. Ophthalmology 109(12):2256-2260

10. Towler HM, Mccluskey P, Shaer B, Lightman S (2000) Long-term follow-up of trabeculectomy with intraoperative 5 -fluorouracil for uveitis-related glaucoma. Ophthalmology 107(10):1822-1828

11. Noble J, Derzko-dzulynsky L, Rabinovitch T, Birt C (2007) Outcome of trabeculectomy with intraoperative mitomycin C for uveitic glaucoma. Can J Ophthalmol 42(1):89-94

12. Iwao K, Inatani M, Seto T et al (2014) Long-term outcomes and prognostic factors for trabeculectomy with mitomycin $\mathrm{C}$ in eyes with uveitic glaucoma: a retrospective cohort study. J Glaucoma 23(2):88-94

13. Bettis DI, Morshedi RG, Chaya C, Goldsmith J, Crandall A, Zabriskie N (2015) Trabeculectomy with Mitomycin Cor Ahmed valve implantation in eyes with uveitic glaucoma. J Glaucoma 24(8):591-599

14. Iverson SM, Bhardwaj N, Shi W et al (2015) Surgical outcomes of inflammatory glaucoma: a comparison of trabeculectomy and glaucomadrainage-device implantation. Jpn J Ophthalmol 59(3):179-186

15. Budenz DL, Barton K, Feuer WJ et al (2011) Treatment outcomes in the Ahmed Baerveldt Comparison Study after 1 year of follow-up. Ophthalmology 118(3):443-452

16. Rockwood EJ (2016) The Ahmed Baerveldt Comparison (ABC) Study: long-term results, successes, failures, and complications. Am J Ophthalmol 163:xii-xiv

17. Christakis PG, Kalenak JW, Zurakowski D et al (2011) The Ahmed Versus Baerveldt Study: one-year treatment outcomes. Ophthalmology 118(11): 2180-2189

18. Christakis PG, Zhang D, Budenz DL et al (2017) Five-year pooled data analysis of the Ahmed Baerveldt Comparison Study and the Ahmed Versus Baerveldt Study. Am J Ophthalmol 176:118-126

19. Coleman AL, Hill R, Wilson MR et al (1995) Initial clinical experience with the Ahmed Glaucoma valve implant. Am J Ophthalmol 120(1):23-31

20. Riva I, Roberti G, Katsanos A, Oddone F, Quaranta L (2017) A review of the Ahmed glaucoma valve implant and comparison with other surgical operations. Adv Ther 34(4):834-847

21. Schwartz KS, Lee RK, Gedde SJ (2006) Glaucoma drainage implants: a critical comparison of types. Curr Opin Ophthalmol 17(2):181-189

22. Gedde SJ, Schiffman JC, Feuer WJ, Herndon LW, Brandt JD, Budenz DL (2007) Treatment outcomes in the tube versus trabeculectomy study after one year of follow-up. Am J Ophthalmol 143(1):9-22

23. Barton K, Gedde SJ, Budenz DL, Feuer WJ, Schiffman J (2011) The Ahmed Baerveldt Comparison Study methodology, baseline patient characteristics, and intraoperative complications. Ophthalmology 118(3):435-442

24. Christakis PG, Tsai JC, Zurakowski D, Kalenak JW, Cantor LB, Ahmed II (2011) The Ahmed Versus Baerveldt Study: design, baseline patient characteristics, and intraoperative complications. Ophthalmology 118(11):2172-2179

25. Anderson JM (1988) Inflammatory response to implants. ASAIO Trans 34(2): 101-107

26. Ayyala RS, Harman LE, Michelini-norris B et al (1999) Comparison of different biomaterials for glaucoma drainage devices. Arch Ophthalmol 117(2):233-236

27. Assaad MH, Baerveldt G, Rockwood EJ (1999) Glaucoma drainage devices: pros and cons. Curr Opin Ophthalmol 10(2):147-153

28. Tanito M, Sano I, Ohira A (2015) Possible bidirectional flow of aqueous fluid after Baerveldt glaucoma implant surgery. Acta Ophthalmol 93(3): e237-e238 
29. Ayyala RS, Zurakowski D, Monshizadeh R et al (2002) Comparison of doubleplate Molteno and Ahmed glaucoma valve in patients with advanced uncontrolled glaucoma. Ophthalmic Surg Lasers 33:94-101

30. Heuer DK, Lloyd MA, Abrams DA et al (1992) Which is better? One or two? A randomized clinical trial of single-plate versus double-plate Molteno implantation for glaucomas in aphakia and pseudophakia. Ophthalmology 99:1512-1519

31. Lloyd MA, Baerveldt G, Fellenbaum PS et al (1994) Intermediate-term results of a randomized clinical trial of the 350 - versus the $500-\mathrm{mm} 2$ Baerveldt implant. Ophthalmology 101:1456-1463 discussion 1463-1464

32. Hong CH, Arosemena A, Zurakowski D, Ayyala RS (2005) Glaucoma drainage devices: a systematic literature review and current controversies. Surv Ophthalmol 50(1):48-60

33. Epstein $\mathrm{E}$ (1959) Fibrosing response to aqueous. Its relation to glaucoma. $\mathrm{Br}$ J Ophthalmol 43:641-647

\section{Submit your manuscript to a SpringerOpen ${ }^{\odot}$ journal and benefit from:}

- Convenient online submission

Rigorous peer review

- Open access: articles freely available online

- High visibility within the field

- Retaining the copyright to your article

Submit your next manuscript at $\gg$ springeropen.com 